www.jmscr.igmpublication.org

Impact Factor 5.84

Index Copernicus Value: 83.27

ISSN (e)-2347-176x ISSN (p) 2455-0450

crossref DOI: https://dx.doi.org/10.18535/jmscr/v5i4.30

\begin{abstract}
Journal Of Medical Science And Clinical Research
IGM Publication

An official Publication of IGM Publication
\end{abstract}

\title{
Comparative Study of Stapler Haemorrhoidopexy and Open Haemorrhoidectomy
}

\author{
Authors \\ Dr Vivek Maurya, Dr Vimal Jain, Dr Shalit Jolly, Dr Rahul Kumar Rai \\ Department of General Surgery, Mata Chanan Devi Hospital, Janakpuri, New Delhi
}

\begin{abstract}
Post-operative pain is most common problem in haemorrhoid surgery. There are various methods available for treatment of haemorrhoids but none of the methods are good for post-operative pain control. Newer method to control the post-operative pain is stapler surgery.

Method and Material- A hospital-based comparative study was carried out in 60 patients, were divided in two groups, 30 patients in each group, which were presented in department of General Surgery, Mata Chanan Devi hospital, New Delhi, during the time period of June 2014-dec2015. It is a 210 bedded, tertiary care hospital in west Delhi, where the patients travel from all northern India.

Result- In the present study attempt has been made to compare the Open Haemorrhoidectomy (group A) with the new modality of Stapler Haemorrhoidopexy (group B)for the treatment of distressing and widely prevalent disease of Hemorrhoids. An attempt has been made to assess the role of Stapler in the treatment of Grade III and IV Hemorrhoids, thereby, trying to highlight the advantages and disadvantages of this new method. In our study the two groups of patients were matched with respect to age. Mean age in group A was $41.93 \pm 13.76$ years and in group $B$ was $48.37 \pm 13.25$ years. There was no statistical difference in the mean age group between the two groups. The haemorrhoidal disease was more common in males as compared to females.Third degree haemorrhoids were the commonest haemorrhoids requiring surgical treatment as reported in various studies. In the present study 39 of 60 patients $(65 \%)$ had grade III haemorrhoids. The most common complaint of the patients were bleeding (76.67\%).More than $50 \%$ of patients had constipation as an associated condition at some point of time and (65.22\%) had a fissure. There was a significant difference in the operative time in the two techniques In group A mean operative time was $26.77+5.25 \mathrm{~min}$ as against $47.33+5.87$ min in group B with a p-value of $<0.001$ (significant).The Post-operative bleeding was significantly less in the stapled group 3(10.00\%) as compared to the open group 11(36.67\%) (Tabel-7). The calculation of the hospital stay was made from the day of surgery. The duration of stay in the hospital was significantly less in group A (mean 1.13+0.43 days) as compared to group B (mean 1.8+ 0.71 days) with $p$ value of $<0.005$.The VAS pain scores to access Post-operative pain were lesser in group $A$ than group $B$ with statistical significance $(6.33 \pm 0.76$ versus $6.87 \pm 0.73, P$ value $<0.01)$ in the first day, $(4.00 \pm$ 0.64 versus $4.80 \pm 0.92$, $P$ value $<0.0004)$ third day, $(2.23 \pm 0.63$ versus $2.97 \pm 0.89, P$ VALUE<0.001) seventh day, $\left(0.67 \pm 0.66\right.$ versus $1.57 \pm 0.57, P$ VALUE<0.001) $14^{\text {th }}$ day and $(0.37 \pm 0.56$ versus $1.2 \pm 0.85, P$ value $<0.0001$ ) at third month (Tabel 9). The requirement of analgesics during the hospital stay as well as after discharge was less in group A. The pain scores compared between the two groups in various studies conclusively proved that the post-operative pain is much less after stapled haemorrhoidectomy than after open haemorrhoidectomy. The calculation of cost of stapler haemorrhoidectomy was significantly higher (P
\end{abstract}


vale $<0.0005)$ as compared to open haemorrhoidectomy but most of the authors noticed cost savings are difficult to measure when not combined with the possible socioeconomic advantages of faster rehabilitation; however, the crude cost analysis in this randomized, controlled trial has demonstrated an advantage of stapled anopexyvs. open haemorrhoidectomy. The savings may be even greater.

Conclusion- Stapled procedure for hemorrhoids is superior to Milligan-Morgan haemorrhoidectomy (open haemorrhoidectomy) in terms of postoperative pain, operative time and return to normal activity. It is straightforward and easy to learn. Early functional and symptomatic outcomes have been satisfactory and appear similar or better to those achieved using conventional technique. However, long term follow-up with respect to these factors is required.

\section{Introduction}

Haemorrhoids are the most common anorectal condition defined as the symptomatic enlargement and distal displacement of the normal anal cushions. They affect most of the people around the World, and represent a major medical problem. Various factors involved in haemorrhoids development include constipation and prolonged straining. The abnormal dilatation and distortion of the vascular channel, together with destructive changes in the supporting connective tissue within the anal cushion, results in formation of haemorrhoids ${ }^{1}$.It is said that 40 percent of population have symptoms due to Haemorrhoids at some time of their lives, a price possibly man has to pay following the evolution of this erect posture ${ }^{2}$.By common consent the terms 'haemorrhoids' and 'piles' are used quite interchangeably, but etymologically the words have entirely different meaning. The term "haemorrhoid" is derived from the Greek adjective "haemorrhoids", meaning bleeding (haima = blood, rhoos=flowing), and emphasizes the most prominent symptom in the majority of cases. It was first used by Hippocrates in his treatise but it cannot be accurately applied to all the conditions diagnosed as haemorrhoids, for a number of them do not at any time give rise to bleeding ${ }^{3}$.The word Pile is derived from "pila", this term was first used by John Ardene (1910) and can be aptly used for all forms of haemorrhoids or piles. The word Pile is derived from "pila", a ball. A number of them do not at any time give rise to bleeding. Though every such condition does produce a swelling of some kind, even though it may not show externally ${ }^{4}$.Vascular cushions within the anal canal do not differ anatomically in normal individuals from those in symptomatic patients. It is therefore probably illogical to talk about the incidence of vascular cushions since they are ubiquitous. Both sexes, all races and all ages have anal cushions. If the cushions are omnipresent then it is only the existence of symptoms that merits classifications as a disease. Hundred percent of population has haemorrhoids but only fifty percent are symptomatic $^{5}$. The treatment of haemorrhoids dates back to antiquity for the two chief symptoms of bleeding and protrusion. The methods of treatment date back to the Babylonian era, Hippocrates described the treatment by cautery, which must have been extremely painful in the pre-anaesthetic era ${ }^{6}$. This has been mentioned in "Sushruta Samhita" of the ancient Indian medicine. At present a wide variety of treatment is available for haemorrhoidal disease, ranging from advice on diet and bowel habit, through a number of procedure like mucosal fixation and widening of the anus, to different techniques of excision of the internal anal vascular cushions and the external anal vascular channels. The choice of surgery depends on the severity, type of the symptoms, degree of prolapse, the expertise of the operator and equipments available. About $40 \%$ of the patients suffering from haemorrhoids require surgery ${ }^{7}$. Conventional haemorrhoidectomy is a commonly performed operation. It has good results but is a very painful procedure resulting in a hospital stay of four to ten days and time off work for two to six weeks ${ }^{8}$. The patient also faces the complications of haemorrhage, urinary retention and late complications like 
stenosis or incontinence. In search of a newer surgical technique to treat the haemorrhoids, stapler has been introduced for haemorrhoidectomy. Stapled haemorrhoidopexy has come up as a new and promising procedure causing minimal postoperative pain, early discharge and quick return to work.

Objective-Objective of the study was to determine the efficacy and benefits of the new procedure for haemorrhoids against conventional open technique.

\section{Primary Objective - Compare post-operative pain}

\section{Secondary Objective}

1. Duration of surgery

2. Duration of the hospital stay

3. Post-operative bleeding

4. Cost of the procedure

\section{Material Methods}

\section{Study Area}

The study was conducted in the Department of General Surgery, Mata Chanan Devi Hospital, New Delhi, in patients who will undergone haemorrhoidectomy by stapler or open method.

Study Design\& Duration of Study:

The study was Hospital based Non Randomized comparative Study analysis of symptomatic haemorrhoid patients, presented in Mata Chanan Devi hospital. The study was conducted from June 2014 to December2015

\section{Sample size and Sample technique:}

One of the most important symptoms of haemorrhoidectomy is the pain experienced by the patient after operation which is quantified in terms of visual analog scale (VAS) pain score. On the basis of previous authors, we assumed that the difference of 1 in VAS (post-operative pain) in patients between stapler and open haemorrhoidectomy in grade $3 \mathrm{rd}$ and $4^{\text {th }}$ degree of haemorrhoids is considered clinically significant. At 2-sided type 1 error of $0.05,90 \%$ power and $\mathrm{SD}$ of 1 , the minimum required sample size is 22 patients in each study group. So to reduce margin of error, total sample size taken is 60 (30 patients in each group).

Formula used is:-

1) For comparing mean of two groups

$\mathrm{N}>=2$ (standard deviation) $2 *(Z \alpha+Z \beta) 2$

(Mean difference) 2

Where $Z \alpha$ is value of $Z$ at two sided alpha error of $5 \%$ and $Z \beta$ is value of $Z$ at power of $90 \%$ and mean difference is difference in mean values of two groups.

Study population: The patients involved in the study were 3rd and 4th grade haemorrhoids with no age and sex bar during June. 2014 to December. 2015

\section{Inclusion Criteria}

1. Third and Fourth degree haemorrhoids

2. Failure of conservative treatment of Second degree haemorrhoids

3. Haemorrhoids with fissure in ano

4. Haemorrhoids with fistula in ano

\section{Exclusion Criteria}

1. First and second degree haemorrhoids

2. Other comorbid conditions

\section{Observations}

A total of 60 patients were included in the study. Group A (SH): Those who underwent Stapler haemorrhoidectomy $(\mathrm{n} 1=30)$

Group B (OH): Those who underwent open haemorrhoidectomy (n2 = 30)

Following observations were made:

1. Patients characteristics - age and sex

2. Duration of surgery

3. Post-operative pain scores (at $24 \mathrm{hrs} .3$ days, 7 days, 14thdays 3rd month.)

4. Duration of hospital stay

5. Post-operative bleeding

6. Cost of the procedure 


\section{Preoperative Data}

\section{Age Distribution}

The youngest patient $22 \mathrm{yrs}$. and the oldest one was $75 \mathrm{yrs}$. in the study.

Tabel No.1: Age Distribution

\begin{tabular}{|l|c|c|c|}
\hline Age & SH(group A) $(\mathrm{n}=30)$ & OH(group B) $(\mathrm{n}=30)$ & \\
\cline { 1 - 3 } Mean \pm Stdev & $41.93 \pm 13.76$ & $48.37 \pm 13.25$ & \multirow{2}{*}{0.099} \\
\hline Median & 43 & 48.5 & \\
\hline Min-Max & $25-64$ & $22-75$ & \\
\hline Inter quartile Range & $28-54$ & $40-52$ & \\
\hline
\end{tabular}

Mean age of patients who underwent haemorrho-

$P$ vale $=0.099$ i.e. $>0.05$

idectomy in group $\mathrm{A}(\mathrm{SH})$ was $41.93 \pm 13.76 \mathrm{yrs}$.

Hence, the age difference in group A and group B And group B $(\mathrm{OH}) 48.37 \pm 13.25$. was not statistically significant.

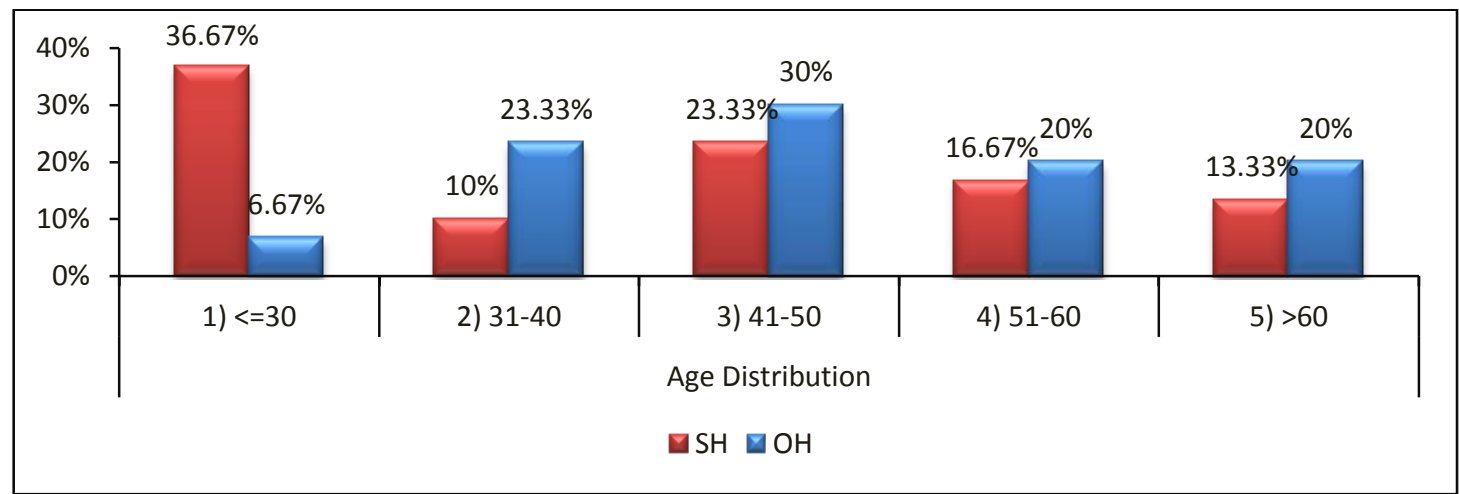

\section{Age Distribution (group wise)}

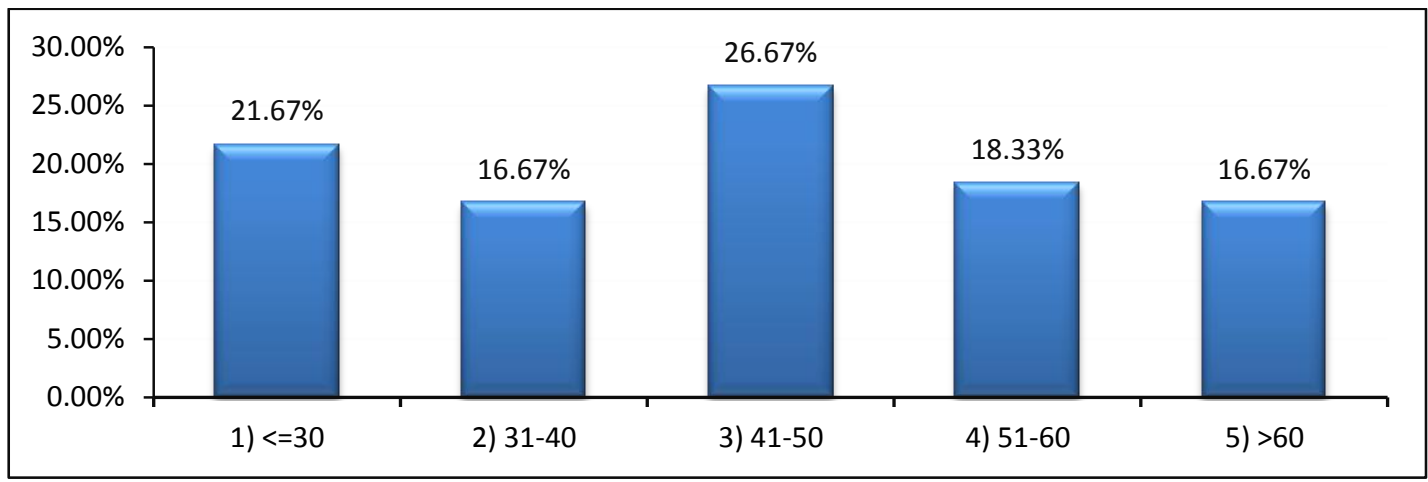

Age distribution (over all)

\section{Gender Distribution}

Out of 60 patients 40 were males. In group A $(\mathrm{SH})$ $33.33 \%$ were females and $66.67 \%$ males. In group $\mathrm{B}(\mathrm{OH})$ the frequency of female gender was
$33.33 \%$ and male gender was $66.67 \%$. There was no statistic difference $(\mathrm{P}=1.000)$ between the two groups according to gender. $\mathrm{P}$ value was significant.

Tabel No.2 Gender Distribution

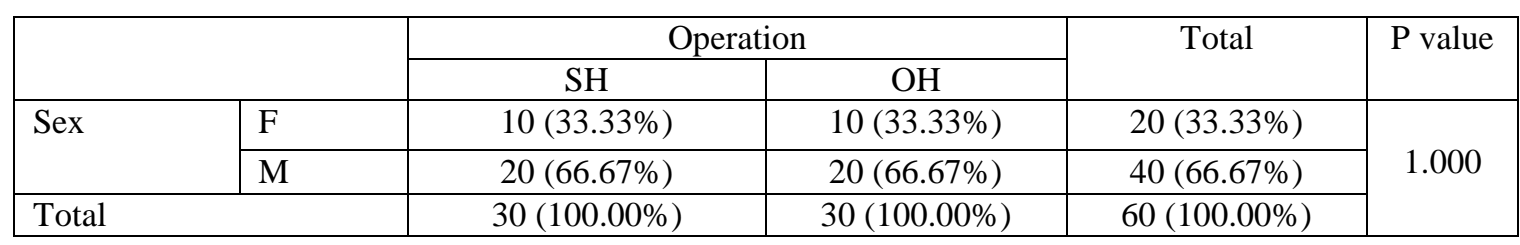




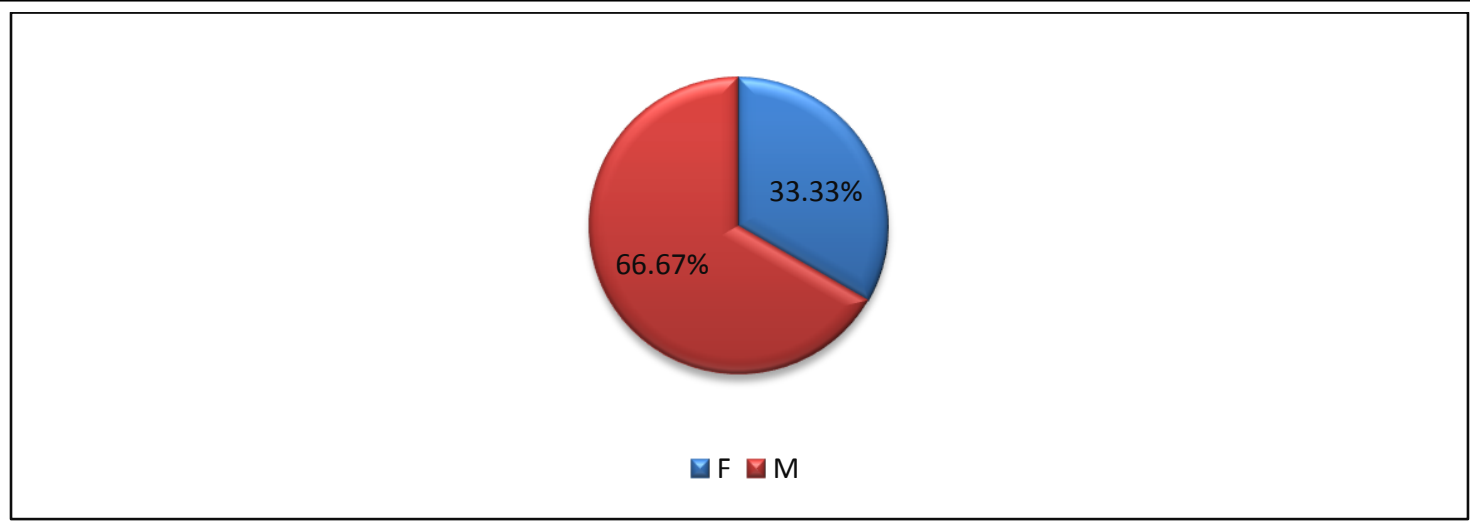

Gender distribution $(\mathrm{F}=$ Female, $\mathrm{M}=$ Male $)$

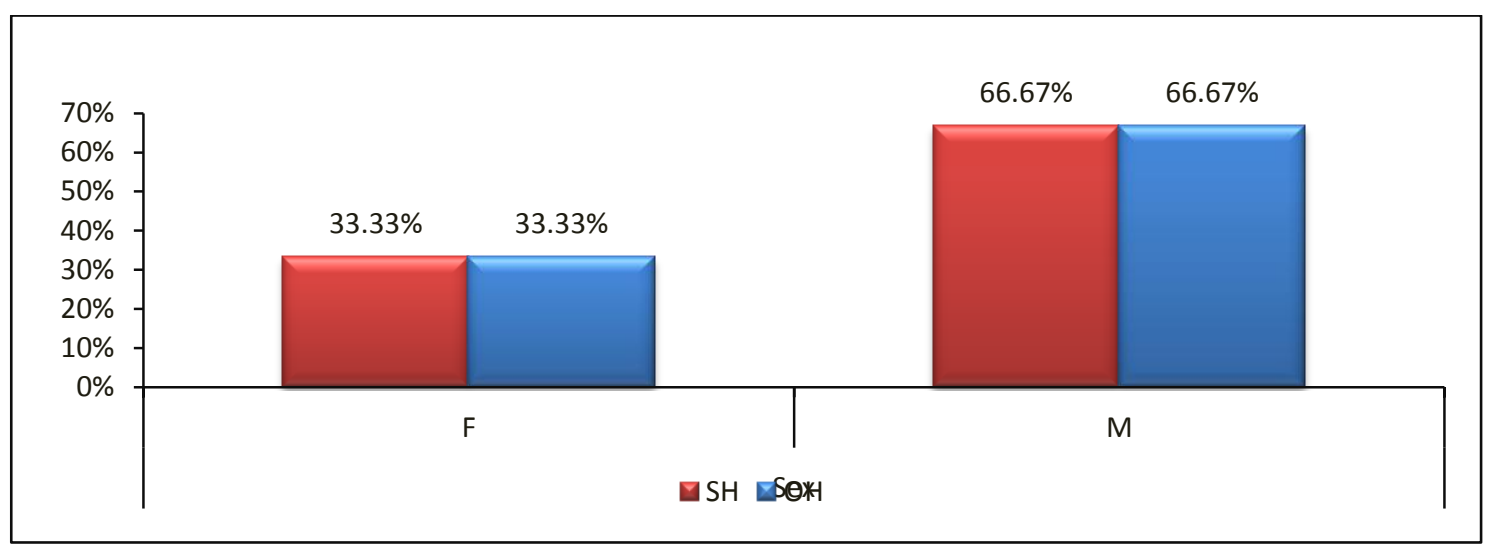

Bar chart of group wise gender distribution

\section{Grades of Haemorrhoids.}

In the present study 39 of 60 patients $(65 \%)$ had grade 3 Haemorrhoids.

Tabel No.3 Grades of Haemorrhoids.

\begin{tabular}{|c|c|c|c|c|c|}
\hline & \multicolumn{2}{|c|}{ Operation } & \multirow[t]{2}{*}{ Total } & \multirow[t]{2}{*}{$\mathrm{P}$ value } \\
\hline & & SH & $\mathrm{OH}$ & & \\
\hline \multirow[t]{2}{*}{ Grading } & 3 & $19(63.33 \%)$ & $20(66.67 \%)$ & $39(65.00 \%)$ & \multirow{3}{*}{0.787} \\
\hline & 4 & $11(36.67 \%)$ & $10(33.33 \%)$ & $21(35.00 \%)$ & \\
\hline Total & & $30(100.00 \%)$ & $30(100.00 \%)$ & $60(100.00 \%)$ & \\
\hline
\end{tabular}

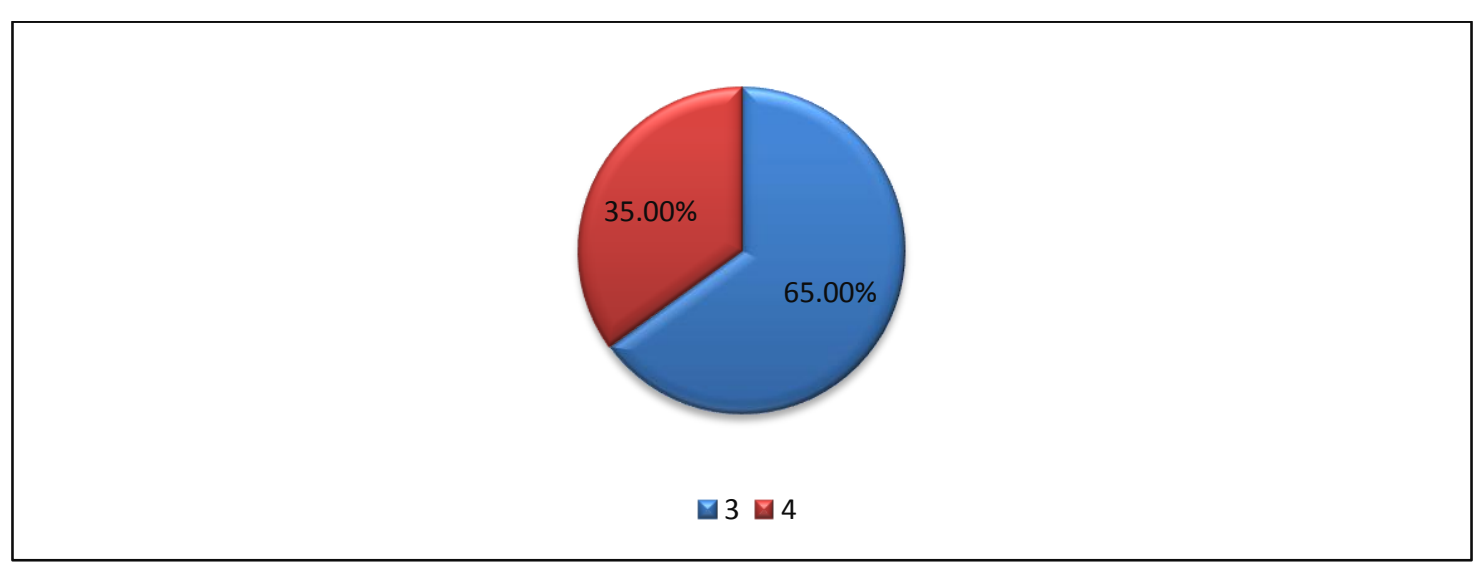

Grading Distribution (3= grade three haemorrhoid, 4= grade four haemorrhoid) 


\section{Most common complaints}

The most common complaints were bleeding $(76.67 \%)$.

Tabel No.4 Most common complaints

\begin{tabular}{|l|c|c|c|c|}
\hline \multirow{2}{*}{} & \multicolumn{2}{|c|}{ Operation } & \multirow{2}{*}{ Total } & P value \\
\cline { 2 - 3 } & $\mathrm{SH}$ & $\mathrm{OH}$ & & \\
\hline Bleeding & $21(70.00 \%)$ & $25(83.33 \%)$ & $46(76.67 \%)$ & 0.222 \\
\hline Prolapse & $22(73.33 \%)$ & $17(56.67 \%)$ & $39(65.00 \%)$ & 0.176 \\
\hline Pain & $10(33.33 \%)$ & $10(33.33 \%)$ & $20(33.33 \%)$ & 1.000 \\
\hline Constipation & $15(50.00 \%)$ & $16(53.33 \%)$ & $31(51.67 \%)$ & 0.796 \\
\hline Total & $30(100.00 \%)$ & $30(100.00 \%)$ & $60(100.00 \%)$ & \\
\hline
\end{tabular}

\section{Common complaints in haemorrhoids patient}

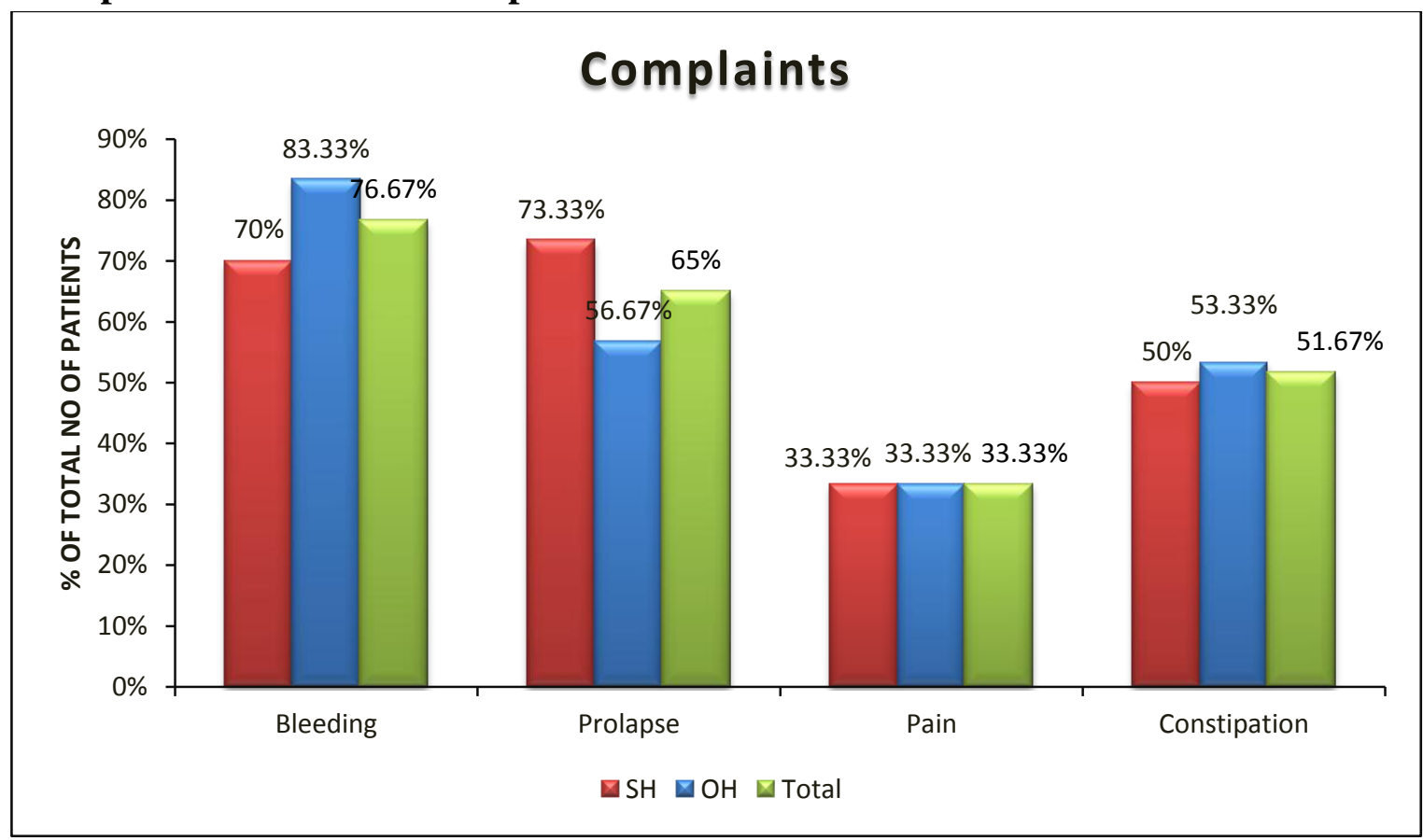

Bar chart of common complaints in haemorrhoids patient (group wise)

\section{Other associated anal pathology (OAAP)}

Fissure was more commonly associated with haemorrhoid then fistula in this study

Tabel No.5 Other Associated Anal Pathology (OAAP).

\begin{tabular}{|c|c|c|c|c|}
\hline & \multicolumn{2}{|c|}{ Operation } & \multirow[t]{2}{*}{ Total } \\
\hline & & SH & $\mathrm{OH}$ & \\
\hline \multirow[t]{2}{*}{ OAC } & FISSURE & $72.73 \%$ & $58.33 \%$ & $65.22 \%$ \\
\hline & FISTULA & $27.27 \%$ & $41.67 \%$ & $34.78 \%$ \\
\hline Total & & $100.00 \%$ & $100.00 \%$ & $100.00 \%$ \\
\hline
\end{tabular}




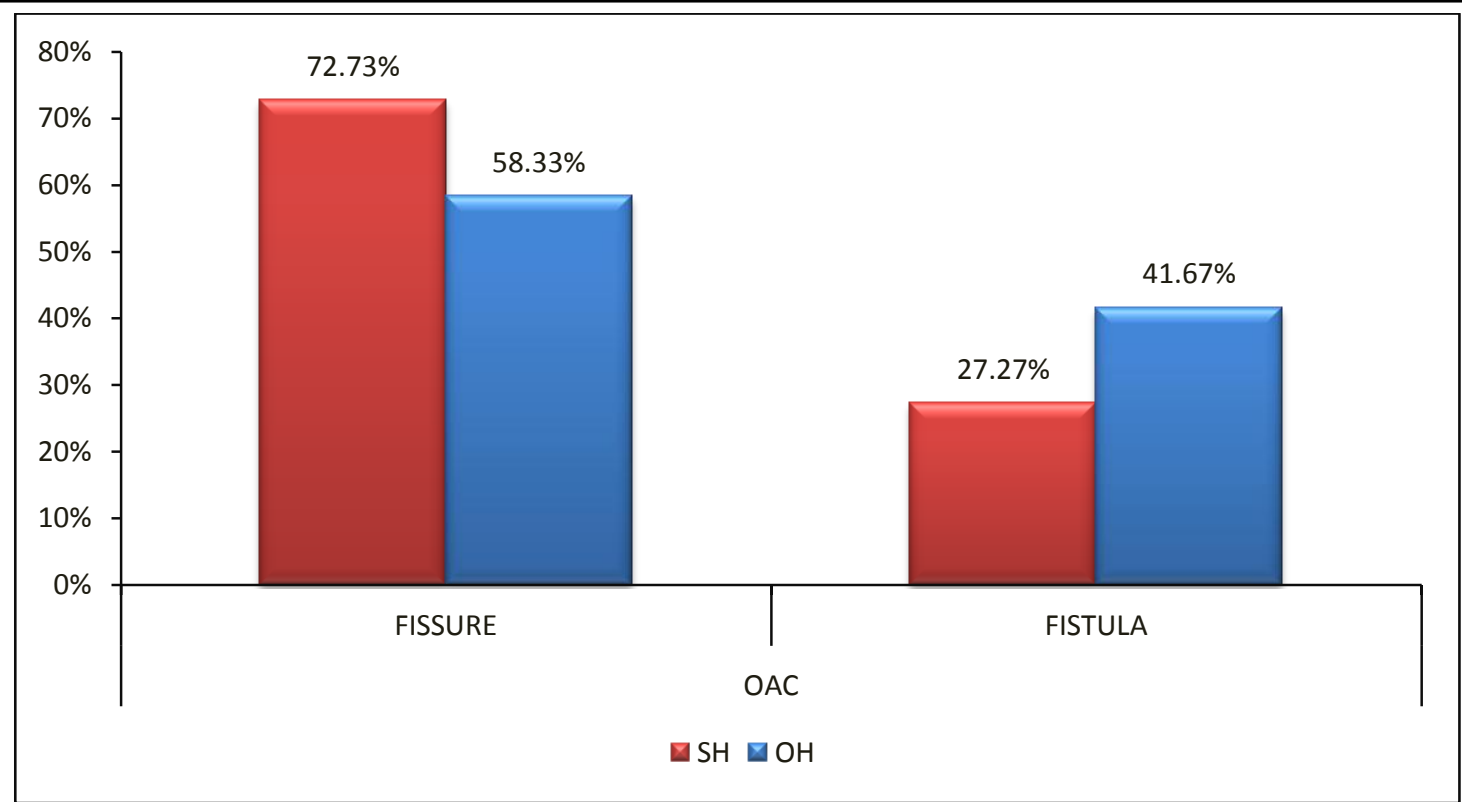

Other Associated Anal Pathology (OAAP) group wise

\section{Operative Data}

\section{Duration of surgery (minutes)}

In comparison with group B, group A have shorter operating time with significant $\mathrm{p}$ value.

Tabel No. 6 Duration of surgery (minutes)

\begin{tabular}{|l|c|c|c|}
\hline Operating Time (min) & SH (Group A) & OH (Group B) & p-value \\
\hline Mean & 26.77 & 47.33 & \multirow{2}{*}{0.001} \\
\hline y SD & 5.25 & 5.87 & 0.001 \\
\cline { 1 - 3 }
\end{tabular}

Mean duration of surgery was significant less in group A with $p<0.001$

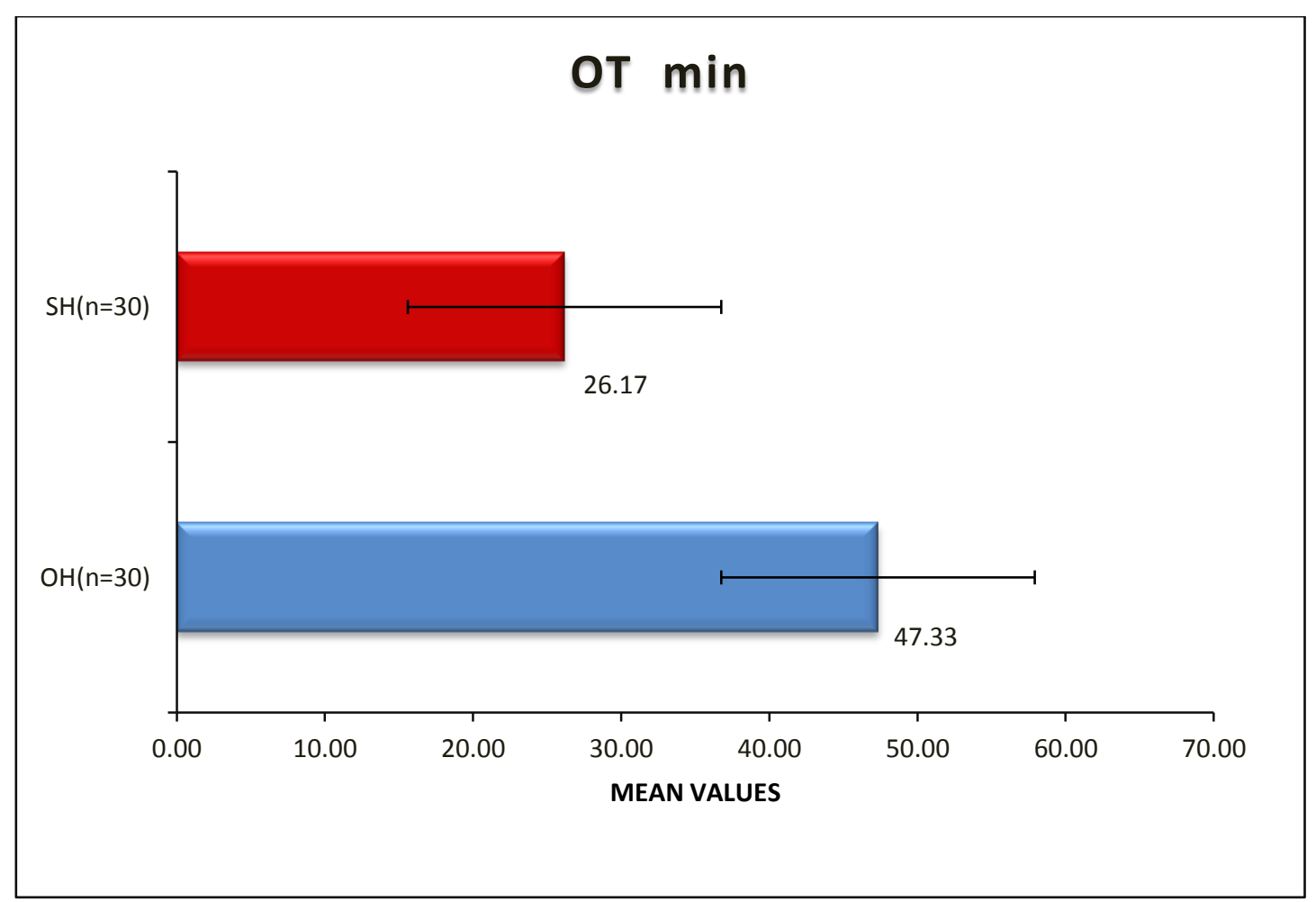

Duration of Surgery group wise (in minutes) 


\section{JMSCR Vol||05||Issue||04||Page 19892-19904||April}

\section{Post Operative Data}

1.Post-operative bleeding in first $24 \mathrm{hr}$ (POB/in

24 hr.)

Post-operative bleeding in first $24 \mathrm{hr}$ was significantly less in group A than group B.
Because $\mathrm{p}$ value was 0.030 which was significantly less than $\mathrm{p}$ value 0.05 .

Tabel No. 7 post-operative bleeding in first 24hr (POB/in $24 \mathrm{hr}$.)

\begin{tabular}{|l|c|c|c|c|c|}
\hline \multirow{2}{*}{\multicolumn{2}{|c|}{}} & \multicolumn{2}{c|}{ Operation } & \multirow{2}{*}{ Total } & \multirow{2}{*}{ P value } \\
\cline { 3 - 5 } \multicolumn{2}{|c|}{ POB/in24hr } & SH (group A) & OH (group B) & & \\
\cline { 2 - 5 } & A & $27(90.00 \%)$ & $19(63.33 \%)$ & $46(76.67 \%)$ & \multirow{2}{*}{0.030} \\
\hline Total & $3(10.00 \%)$ & $11(36.67 \%)$ & $14(23.33 \%)$ & $60(100.00 \%)$ & \\
\hline
\end{tabular}

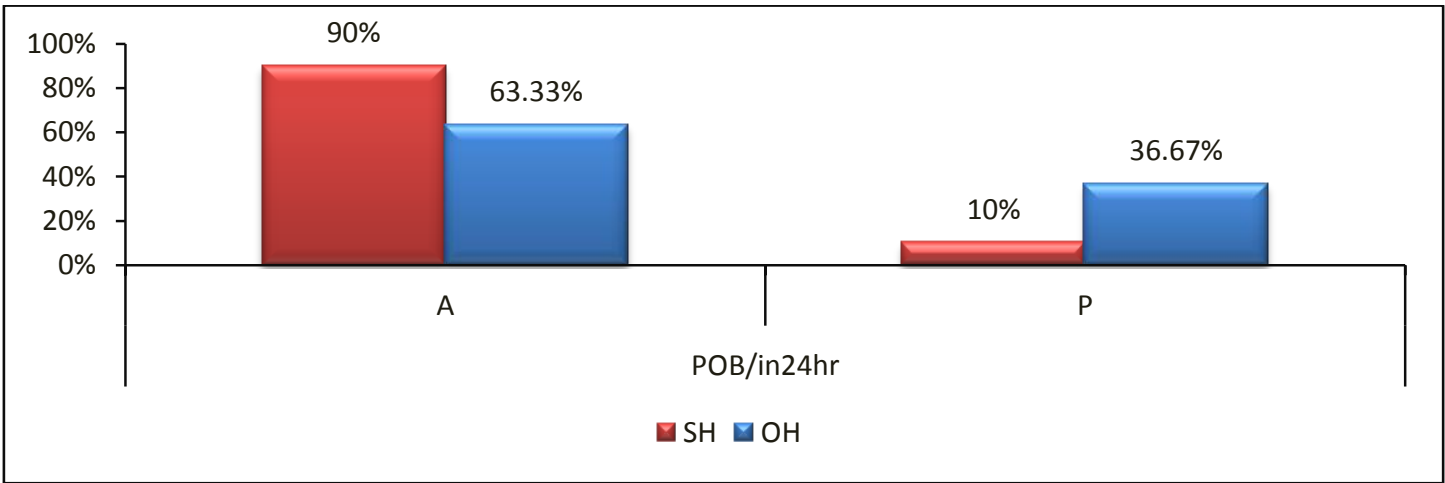

Bar chart showingpost-operative bleeding in first $24 \mathrm{hr}$ group wise (POB/in 24hr.)(A= ABSENT $\mathrm{P}=$ PERSENT)

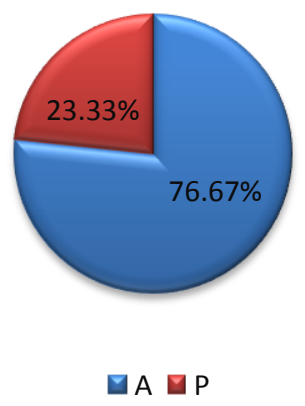

Pie chart showingpost-operative bleeding in first $24 \mathrm{hr}$ group wise (POB/in $24 \mathrm{hr}).(\mathrm{A}=\mathrm{ABSENT}$ $\mathrm{P}=$ PERSENT)

\section{Hospital stay:}

Duration of stay in the hospital was significantly less $(\mathrm{p}<0.0005)$ in group A $(1.13 \pm 0.43$ days $)$ than in group $\mathrm{B}(1.8 \pm 0.71$ days $)$.

Tabel No.8 Hospital stay

\begin{tabular}{|l|c|c|c|}
\hline & SH(group A) & OH(group B) & \multirow{1}{*}{$<.0005$} \\
\cline { 1 - 3 } Mean \pm Stdev & $1.13 \pm 0.43$ & $1.8 \pm 0.71$ & \\
\cline { 1 - 3 } Min-Max & 1 & 2 & \\
\hline Inter quartile Range & $1-3$ & $1-3$ & \\
\hline
\end{tabular}




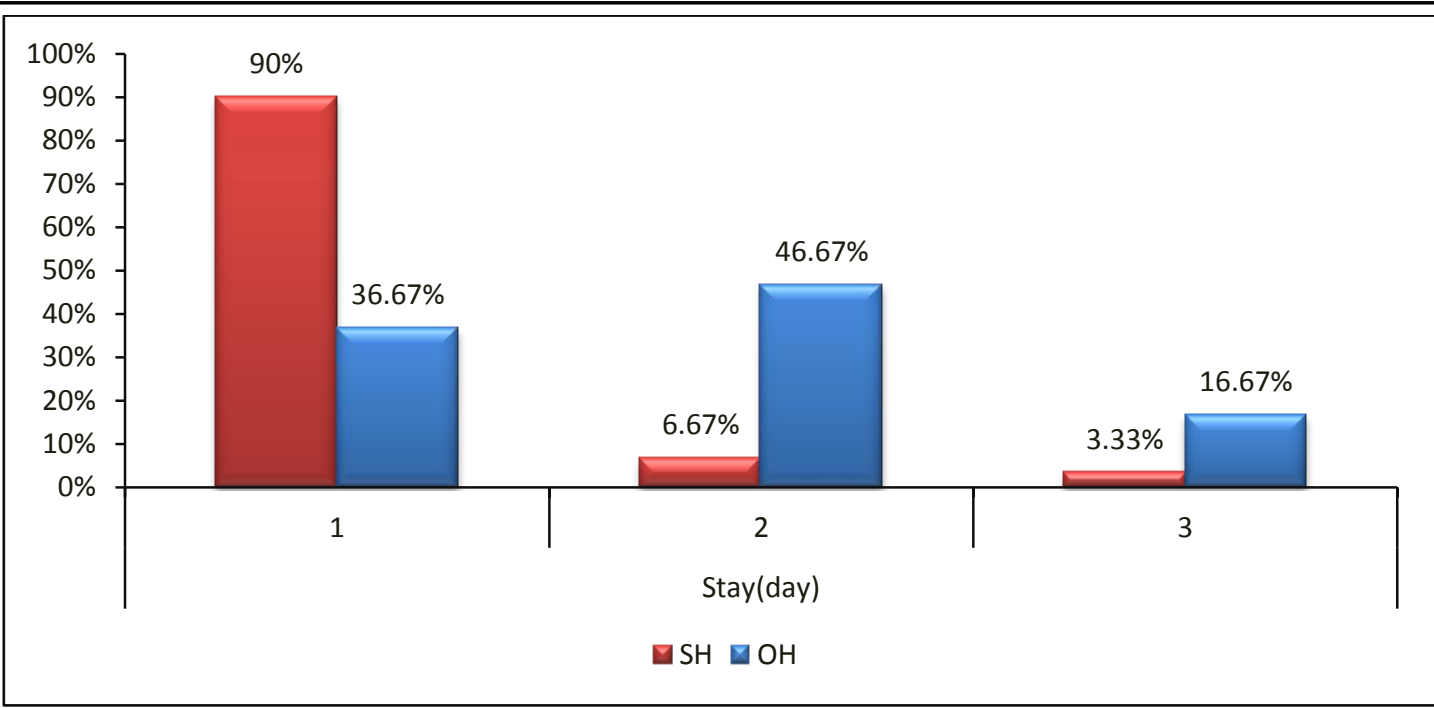

Bar chart showingpost-operative hospital stay (group wise) on day 1, 2, 3

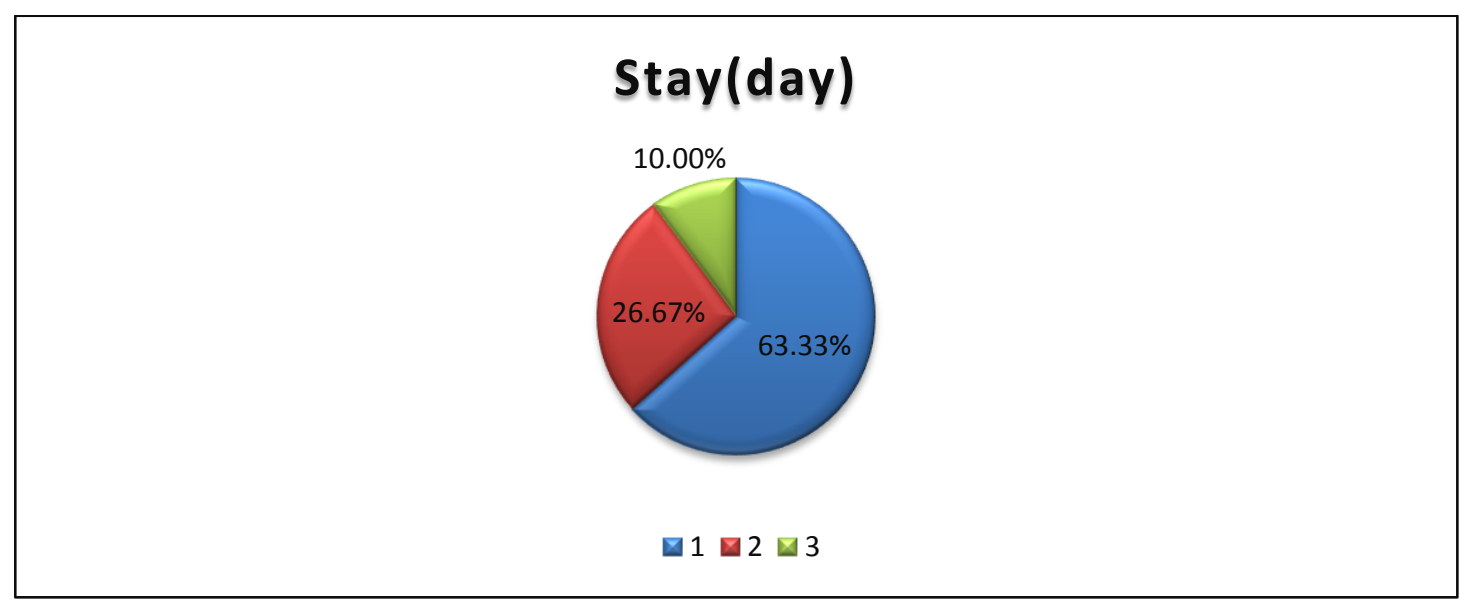

Pie chart showing total hospital stay according to days 1,2 and day3.

3. Pain measurement: according to visual in group $A$ than group $B$, with statistical analogue scale (VAS)

Post-operative pain assessed by visual analogue significance on post-operative day $1,3,7,14$ days score showed significantly less incidence of pain and 3rd. month

Tabel No.9 Pain measurement: according to visual analogue scale (VAS)

\begin{tabular}{|l|c|c|c|}
\hline VAS Day 1 & SH(group A) & OH(group B) & \multirow{2}{*}{0.01} \\
\hline Mean \pm Stdev & $6.33 \pm 0.76$ & $6.87 \pm 0.73$ & \\
\hline Median & 6 & 7 & \\
\hline Min-Max & $5-8$ & $6-8$ & \multirow{2}{*}{0.0004} \\
\hline Inter quartile Range & $6-7$ & $6-7$ & \\
\hline VAS Day 3 & & & \\
\hline Mean \pm Stdev & $4 \pm 0.64$ & $4.8 \pm 0.92$ & \multirow{2}{*}{0.001} \\
\hline Median & 4 & 5 & \\
\hline Min-Max & $3-5$ & $4-6$ & \\
\hline Inter quartile Range & $4-4$ & & \\
\hline VAS Day 7 & & $2.97 \pm 0.89$ & \\
\hline Mean \pm Stdev & $2.23 \pm 0.63$ & $1-4$ & \\
\hline Median & 2 & $2-4$ & \\
\hline Min-Max & $1-3$ & $2-3$ & \\
\hline Inter quartile Range & & & \\
\hline
\end{tabular}




\begin{tabular}{|l|c|c|c|}
\hline VAS Day 14 & & \multirow{2}{*}{0.0001} \\
\hline Mean \pm Stdev & $0.77 \pm 0.73$ & $1.57 \pm 0.57$ & \\
\cline { 1 - 3 } Median & 1 & 2 & \\
\hline Min-Max & $0-2$ & $0-2$ & \\
\hline Inter quartile Range & $0-1$ & $1-2$ & \multirow{2}{*}{0.0001} \\
\hline VAS 3rd month & & & \\
\cline { 1 - 3 } Mean \pm Stdev & $0.37 \pm 0.56$ & $1.2 \pm 0.85$ & \\
\hline Median & 0 & 1 & \\
\hline Min-Max & $0-2$ & $0-3$ & \\
\hline Inter quartile Range & $0-1$ & $1-2$ & \\
\hline
\end{tabular}

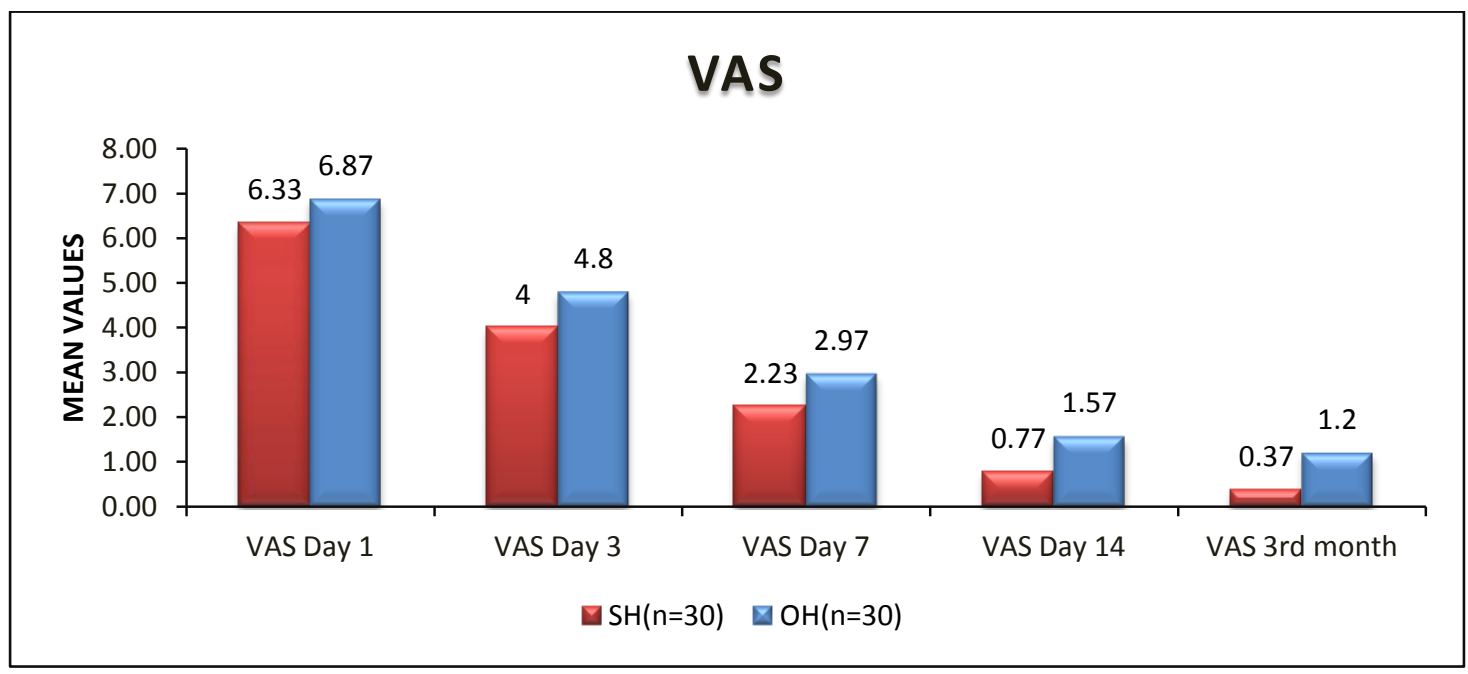

Bar chart showing visual analogue score (VAS) duration wise

\section{Cost of the Procedure}

Here $\mathrm{p}$ value is 0.0005 which is less than 0.05 .

Hence, group A had statistically significant

difference than group B.
It indicates stapler haemorrhoidopexy is more costly than open haemorrhoidectomy.

Table No .10 Cost of the procedure

\begin{tabular}{|l|c|c|c|}
\hline Cost & SH(group A) & OH (group B) & \multirow{2}{*}{$<.0005$} \\
\cline { 1 - 3 } Mean \pm Stdev & $41201.37 \pm 1586.32$ & $12185.17 \pm 728.1$ & \\
\hline Median & 41111.5 & 12097.5 & $10965-13509$ \\
\cline { 1 - 3 } Min-Max & $38450-44000$ & $11675-12864$ & \\
\hline Inter quartile Range & $39875-42006$ & \\
\hline
\end{tabular}

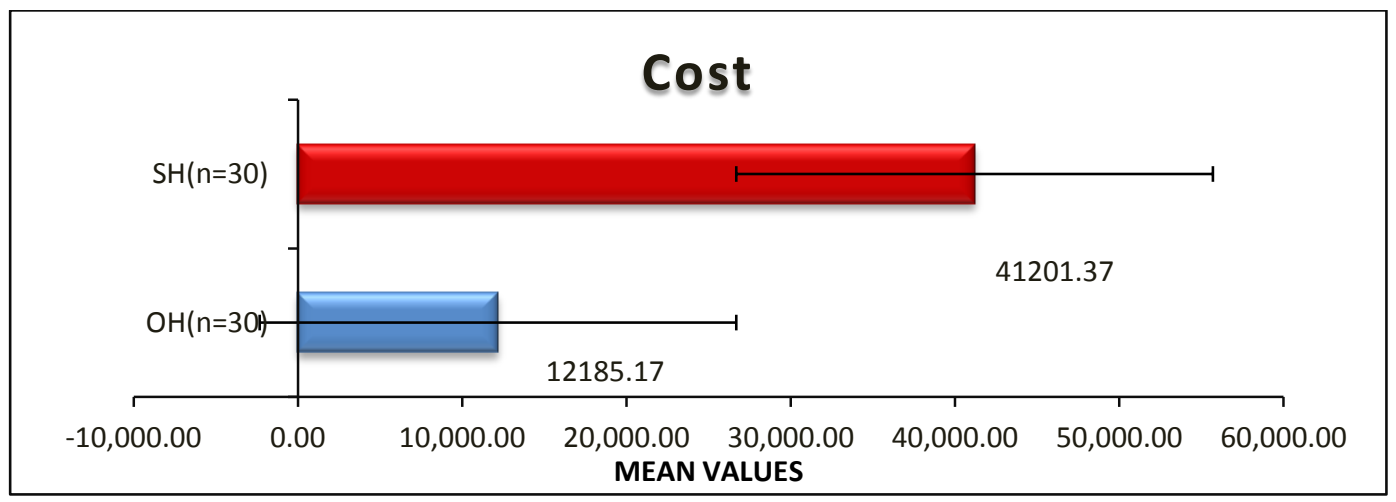

Cost of procedure group wise 


\section{Discussion}

Goligher et al mentioned that haemorrhoids are very common problem in the World, and they noticed that around $40 \%$ of haemorrhoid patients had to undergo haemorrhoidectomy at some time ${ }^{9}$. There are various ways of treatment of haemorrhoids like, rubber band ligation, Injection sclerotherapy, Infra-red photocoagulation and cryotherapy but have poor success rate, so surgery is the main stay of treatment for grade $3^{\text {rd }} \& 4^{\text {th }}$ degree of hemorrhoides ${ }^{10}$. It was observed by some surgeons post-operative pain was quite significant and had kept patients away from work for 2-3 weeks ${ }^{10}$.

Introduction of stapler for haemorrhoids had eliminated most of the above challenges and had also made the surgery for haemorrhoid more patient friendly ${ }^{11}$.

The study was "COMPARITIVE STUDY OF STAPLER HEMORRHOIDOPEXY AND OPEN HAEMORRHOIDECTOMY"designed to determine whether stapled technique offer any definite advantages over open method.

In the present study sixty patients were randomly selected in two groups A and B i.e. those undergoing Stapled haemorrhoidectomy and Milligan Morgan (open) haemorrhoidectomy.

Patients who were part of study excluded from the study had first and second degree haemorrhoids and other comorbid conditions e.g. diabetes mellitus, hypertension. Those included were patients with anal fissure and fistula in ano. Patients were equally distributed in two groups.

The two groups of patients were matched with respect to age. Mean age in group A was $41.93 \pm 13.76$ years and in group $B$ was $48.37 \pm 13.25$ years (Tabel 1). There was no statistical difference in the mean age group between the two groups. There was similar study conducted by Hetzer et al the mean age group was 50.4 yrs in stapled group and 44.8 yrs. in open group- with no statistical difference Mean age group was 48 yrs. and 47 yrs. in the stapled and open groups respectively as evaluated by Ganio et al ${ }^{12}$.Ho and colleagues found the mean age group of 44 years in stapled haemorrhoidectomy patients and 46.3 years in open haemorrhoidectomy patients ${ }^{71}$.

The haemorrhoidal disease was more common in males $^{13}$ as compared to females (Tabel 2) Hetzer reported that the sex distribution of male vs. female was 15:5 in stapled group and 14:6 in open group in his study. This has also been pointed out other studies in the literature.

Third degree haemorrhoids were the commonest haemorrhoids requiring surgical treatment as reported in various studies ${ }^{14}$. In the present study 39 of 60 patients $(65 \%)$ had grade III haemorrhoids (Tabel -3) however the condition of fourth degree haemorrhoids was more common in the study conducted by Shalaby et al ${ }^{76}$.

The most common complaint of the patients were bleeding (76.67\%) (Figure 2) In the study by Ortiz $89 \%$ of patients presented with bleeding. Shalaby reported bleeding as a complaint in $65 \%$ of patients. Ho et al documented bleeding in $80 \%$ of patients ${ }^{73,76 \text {, }}$

More than $50 \%$ of patients had constipation as an associated condition at some point of time and (65.22\%) had a fissure. (Tabel-5) Constipation was an associated compliant in $62 \%$ of patients in the study by Shalaby ${ }^{15}$.

All the patients were operated under spinal anaesthesia in our study however two patients were supplemented with short general anaesthesia because of incomplete effect of spinal anaesthesia, after a routine pre- operative preparation according to the set protocols. In the study by Ganio $46 \%$ of patients were operated under general anaesthesia, 34\% under spinal and 20\% under pudenda block ${ }^{16}$. Mehigan 70 operated all the 22 patients under general anaesthesia. Pavlidis 74 reported all surgeries under epidural aesthesia only Hetzer 73 operated $55 \%$ of patients under general aesthesia and $45 \%$ under spinal aesthesia. Ortiz operated all his patients under spinal aesthesia $^{17}$.

There was a significant difference in the operative time in the two techniques In group A mean operative time was $26.77+5.25 \mathrm{~min}$ as against 
$47.33+5.87 \mathrm{~min}$ in group B with a p-value of < 0.001 (significant) (Tabel-6). It was seen that the duration of surgery showed a downward trend in the stapled group with the increase in the number of cases operated probably because of the learning curve. The point of shorter operative time (Statistically significant) has been well confirmed by a number of studies ${ }^{18}$. However Ho et al required less time in open surgery compared to the stapled technique. This is probably because the study by Ho et al was conducted (1999-2000), when the stapled haemorrhoidectomy was in its earlier stage of learning ${ }^{16}$.

In the present study the patients (PAC fit) were admitted in the morning of surgery day. Mehigan et al also followed similar protocols for admission.

The Post-operative bleeding was significantly less in the stapled group 3(10.00\%) as compared to the open group 11(36.67\%) (Tabel-7). In study by Ganio et al76 secondary haemorrhage occurred in 3 patients each in both groups (of 100 patients each) 1 out of 100 patient (1\%) in stapled group and 2 out of $100(2 \%)$ in open group had significant bleeding as reported by Shalaby(77). Secondary haemorrhage was reported in only one of 28 patients in the conventional haemorrhoidectomy group and none in stapled group by Ortiz ${ }^{15}$. The calculation of the hospital stay was made from the day of surgery. The duration of stay in the hospital was significantly less in group A (mean $1.13+0.43$ days) as compared to group B (mean $1.8+0.71$ days ) with $\mathrm{p}$ value of $<0.005$ (Tabel-8), also supported by the Rowsell et al ${ }^{72}$, Pavlidis et al ${ }^{75}$, Ganio et al ${ }^{77}$ and Shalaby et al 75 . However the duration of stay was similar in the two groups as reported by Mehigan et al ${ }^{14}$, Hetzer et al ${ }^{15}$ and Ho et al ${ }^{16}$.

The VAS pain scores to access Post-operative pain were lesser in group A than group B with statistical significance $6.33 \pm 0.76$ versus $6.87 \pm$ $0.73, \mathrm{P}$ value $<0.01)$ in the first day, $(4.00 \pm 0.64$ versus $4.80 \pm 0.92, \mathrm{P}$ value $<0.0004)$ third day, $(2.23 \pm 0.63$ versus $2.97 \pm 0.89$, P VALUE $<0.001)$ seventh day, $(0.67 \pm 0.66$ versus $1.57 \pm 0.57, \quad \mathrm{P}$
VALUE $<0.001) 14^{\text {th }}$ day and $(0.37 \pm 0.56$ versus $1.2 \pm 0.85, \mathrm{P}$ value $<0.0001)$ at third month (Tabel 9) The requirement of analgesics during the hospital stay as well as after discharge was less in group A. The pain scores compared between the two groups in various studies conclusively proved that the post-operative pain is much less after stapled haemorrhoidectomy than after open haemorrhoidectomy All studies have been unanimous on this point ${ }^{71-78}$.

The calculation of cost of stapler haemorrhoidectomy was significantly higher $(\mathrm{P}$ vale $<0.0005)$ as compared to open haemorrhoid-dectomy but most of the authors noticed cost savings are difficult to measure when not combined with the possible socioeconomic advantages of faster rehabilitation; however, the crude cost analysis in this randomized, controlled trial has demonstrated an advantage of stapled anopexyvs. open hemorrhoidectomy. The savings may be even greater.

\section{Conclusion}

Stapled procedure for hemorrhoids is superior to Milligan- Morgan haemorrhoidectomy (open haemorrhoidectomy) in terms of postoperative pain, operative time and return to normal activity. It is straightforward and easy to learn. Early functional and symptomatic outcomes have been satisfactory and appear similar or better to those achieved using conventional technique. However, long term follow-up with respect to these factors is required.

\section{Recommendations}

We strongly recommend the use of Stapler haemorrhoidopexy in the treatment of third and fourth degree haemorrhoidal disease.

Our study still have several limitations. The number of patients was small and our follow-up period was short. The long-term results and recurrence rate should be evaluated in larger prospective studies that compares the Stapler method to other operative methods. 


\section{References}

1. Mehigan BJ Monson JRT, Hartley JE. Stapling procedure for haemorrhoids versus Milligan- Morgan haemorrhoiddectomy. Randomized controlled trial. Lancet 2000; 355: 782-5

2. Rowsell M, Bello M, Hemingway DM Circumferential mucosectomy (stapled haemorrhoidectomy) versus conventional haemorrhoidectomy randomized controlled trial Lancet 2000; 355: 779-81

3. HoYh, CHEONG wk, Tsang $\mathrm{C}$ et al. Stapled haemorrhoidectomy.- cost and effectiveness: Randomized controlled trial including incontinence scoring, anorectic manometer, and end anal ultrasound assessment al up to three months Dis Colon Rectum 2000; 43: 1666-75

4. Hetzer FH, Demartines N, Handschin AE, Clavien PA. Stapled vs excision haemorrhoidectomy: long-term results of a prospective randomized trial. Archives of Surgery. 2002 Mar 1;137(3):337-40.

5. Pavlidfis T, Papziogas B, Souparis A et al. Modern stapled Longo procedure vs conventional millyan-Margan haemorrhoidectomy. A randomized controlled trial.Int J Colorectal Dis 2002; 17: 50-3.

6. Shelby R, Dusky A Randomized clinical trial of stapled with Milligan- Margan haemorrhoidectomy. Br. J Surg 2001; 88: 1049-53

7. Ganio E, Alto mare DF, Glacially $F$ et al Prospective randomized multicentre trial comparing stapled with open haemorrhoidectomy. Br J SURG 2001; 88:669-74.

8. Ortiz $\mathrm{H}$, Matzo J, Armenderiz P. Randomized Clinical Trial of stapled haemorrhoidopexy versus conventional diathermy haemorrhoidectomy. Br J Surg 2002; 89: 1376-81.
9. Fazio VW. Early promise of the stapling technique for haemorrhoidectomy. Lancet 2000; 355: 768-9

10. Marti Mc. Mechanical haemorrhoiddectomy. Using circular stapler warning to colleagues Swiss Surg 1999; 5: 151-4.

11. Cheetah MJ Mortensen NJM, Nostrum PO et al. Persistent pain and faucal urgency after stapled haemorrhoidectomy. Lancet 2000; 356: 7303.

12. Molloy RG, Kings more D. Life Threatening sepsis after stapled haemorrhoiddectomy. Lancet 2000; 355:810.

13. Mend RK An experience in Bombay with postoperative complication of haemorrhoidectomy. Disc OLON Rectum 1966; 9: 176.

14. Miller H. Postoperative complication of haemorrhoidectomy. Amer J Procrol 1966; 17: 361.

15. Shitake IW et al Emphysema of male genitalia following haemorrhoidectomy. Urology 1975; 5: 647.

16. Laughlan K, Jayne DG, Jackson D, Rupprecht F, Ribaric G. Stapled haemorrhoidopexy compared to MilliganMorgan and Ferguson haemorrhoidectomy: a systematic review. International journal of colorectal disease. 2009 Mar 1;24(3):335-44.

17. Burch J, Epstein D, Baba-Akbari Sari A, Weatherly H, Jayne D, Fox D, Woolacott N. Stapled haemorrhoidopexy for the treatment of haemorrhoids: a systematic review. Colorectal Disease. 2009 Mar 1;11(3):233-43.

18. Sultan S, Rabahi N, Etienney I, Atienza P. Stapled haemorrhoidopexy: 6 years' experience of a referral centre. Colorectal Disease. 2010 Sep 1;12(9):921-6. 